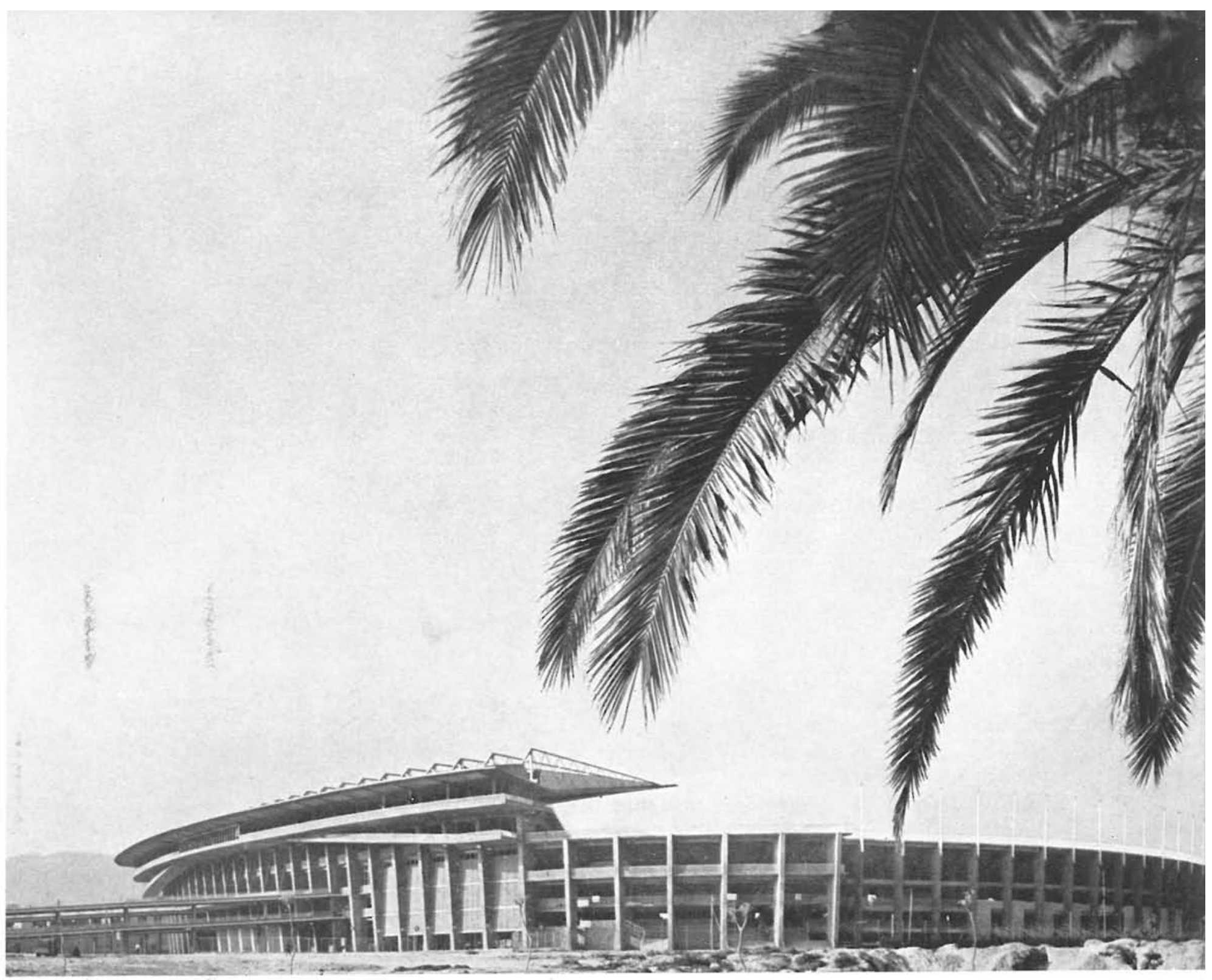

\title{
nuevo estadio, en Barcelona
}

J. SOTERAS MAURI, J. MITJANS MIRÓ, GARCÍA-BARBÓN FERNÁNDEZ DE HENESTROSA, arquitectos

$152 \cdot 33$

El fútbol, en su paso de deporte a espectáculo deportivo, ha traído, como consecuencia, un mayor arrastre de las masas hacia los recintos de juego. Debido a ello, todos los clubs españoles se han visto en la necesidad de ampliar o construir de nuevo sus instalaciones deportivas para poder albergar a esta ingente riada de espectadores.

El Club de Fútbol Barcelona ha terminado recientemente la primera fase de su nuevo estadio con un aforo provisional de noventa mil espectadores y que, cuando esté acabado, tendrá capacidad para ciento cincuenta mil; 0 sea: será uno de los mayores del mundo. El proyecto ha sido estudiado minuciosamente, no sólo en esencia, sino en potencia, ya que el nuevo estadio Gamper se ha incorporado a la panorámica de la ciudad como uno de sus elementos característicos por razón de su masa, aislamiento y singularidad. 
La realización se ha ajustado fielmente al proyecto, con muy escasas variaciones, tales como las de cimentación, obligadas por la naturaleza del terreno, o por la topografía, y la de la estructura de la marquesina, para la cual se adoptó, definitivamente,

la solución de cuchillos de hierro laminado, de $6 \mathrm{~m}$ de anchura en su anclaje, emplazando la lámina de cubierta en el plano medio por razón de esbeltez.

Son característicos de esta construcción, el perfil de los tres graderíos superpuestos,

con voladizos de $12 \mathrm{~m}$ y de $7 \mathrm{~m}$, cubiertos por el de tribuna, de $40 \mathrm{~m}$, desde su anclaje y enlazados al exterior con las dos rampas dobles.

Los dos problemas fundamentales en este tipo de construcciones han sido resueltos perfectamente: la visibilidad y la circulación.

La primera se ha estimado como muy buena desde todos sus ángulos;

y la segunda, importantísima en estas concentraciones, se ha logrado igualmente tanto en el exterior como en el interior.
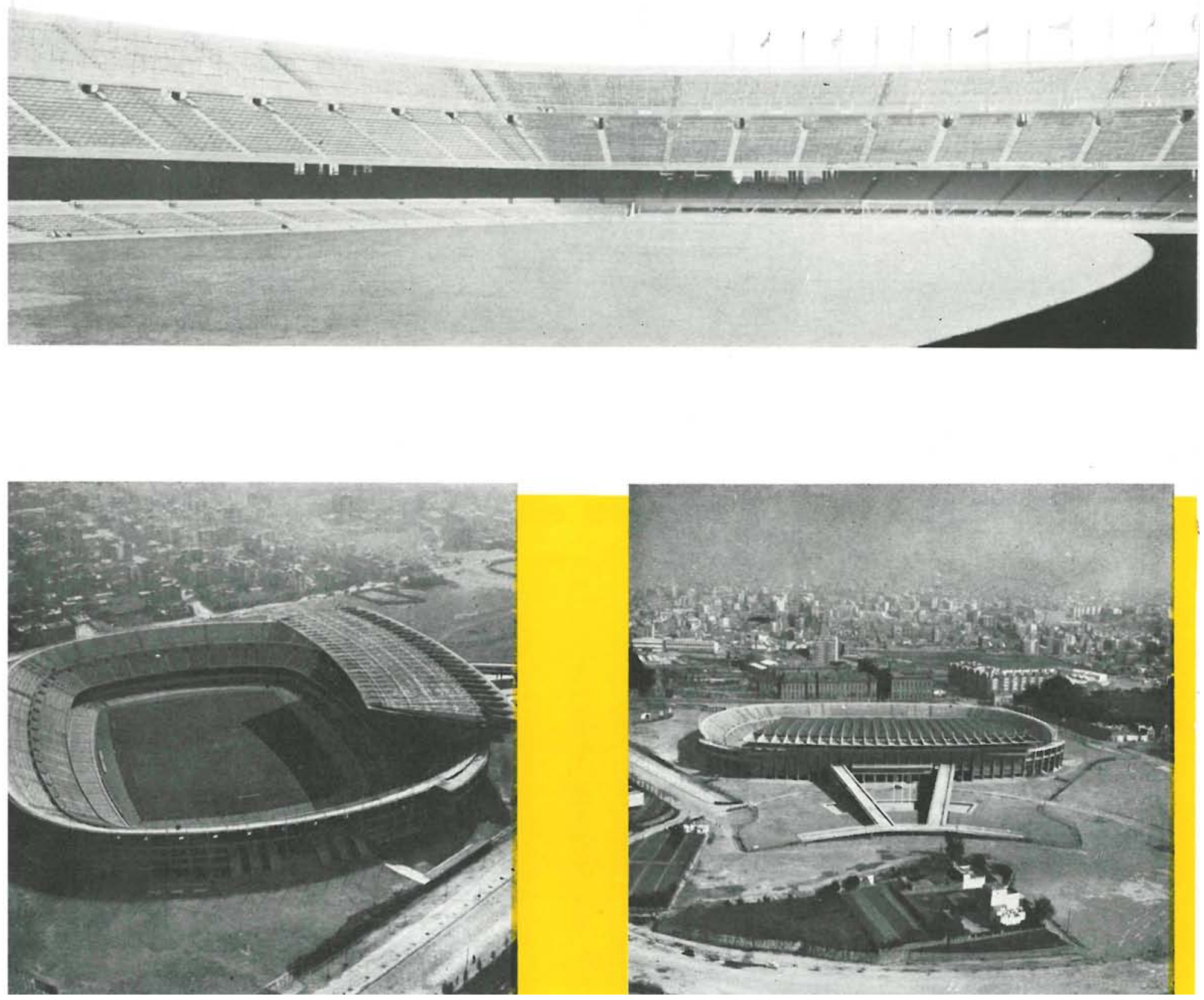

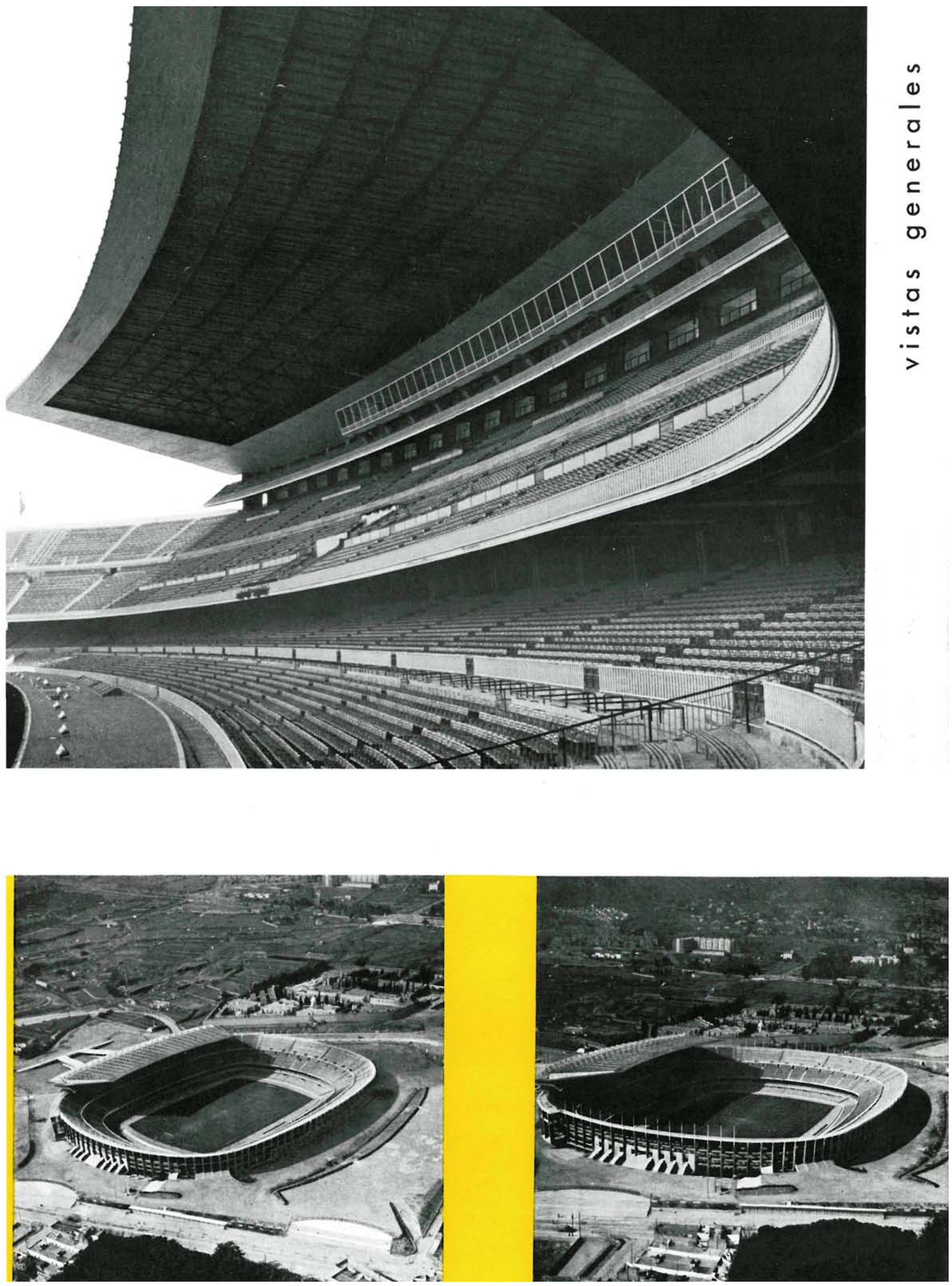

(C) Consejo Superior de Investigaciones Científicas Licencia Creative Commons 3.0 España (CC-by) 


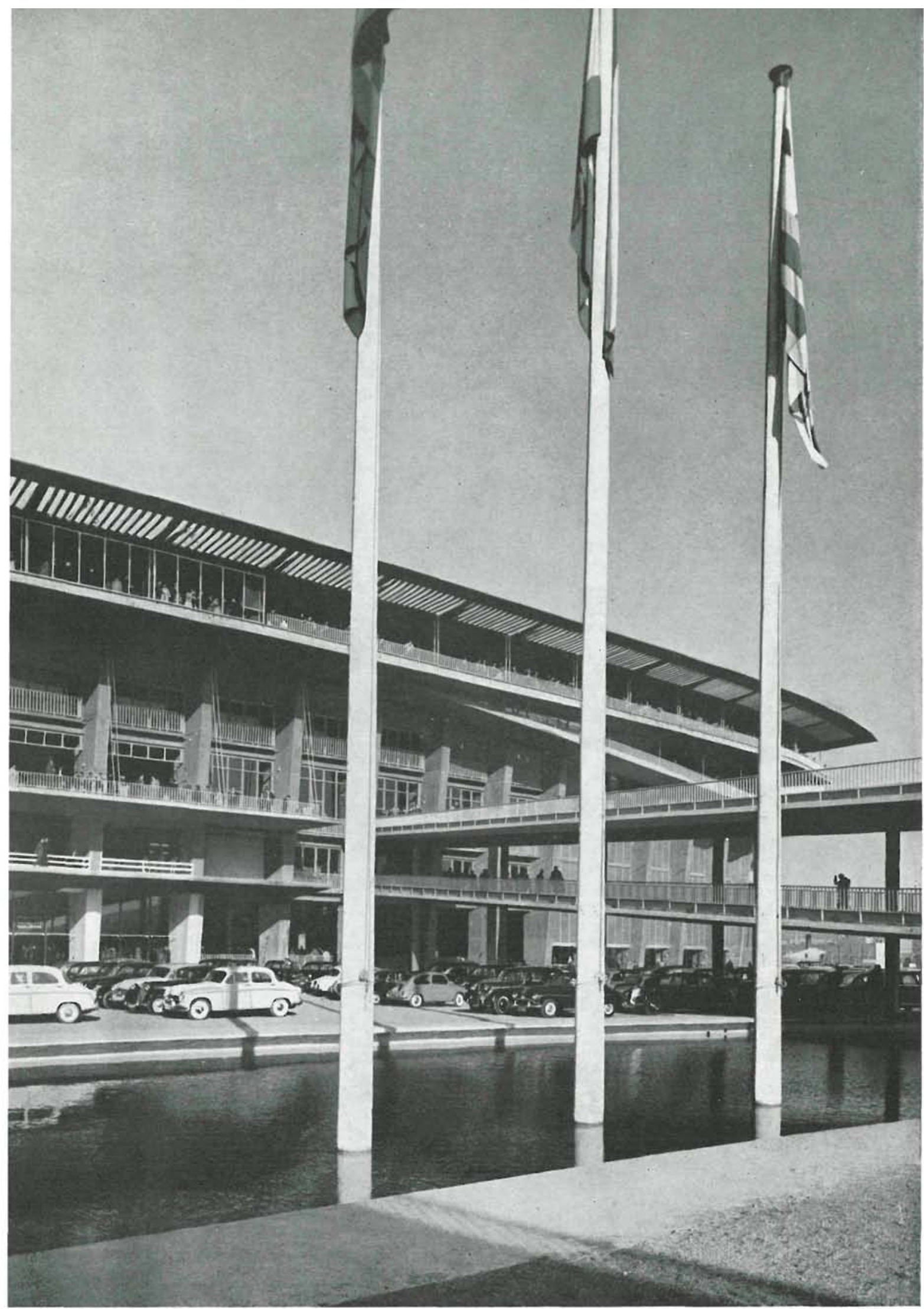

Caben destacarse también el cuidado y esmero con que han sido tratados los servicios e instalaciones, en especial las cabinas de prensa, radio y televisión, las cuales quedan colgadas de la marquesina formando un cuerpo con la misma y dando lugar al atrevido perfil que puede apreciarse en las secciones adjuntas. 

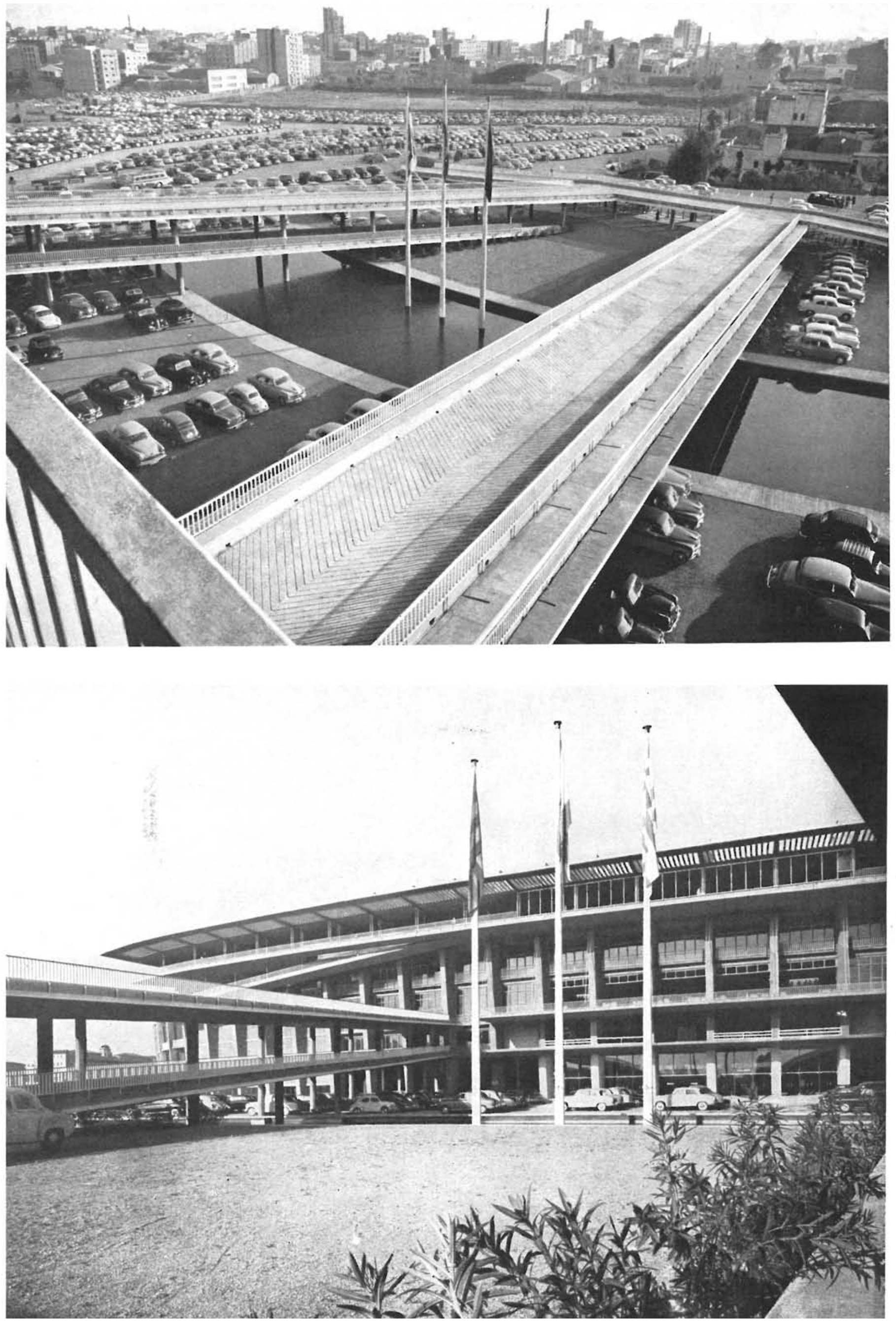


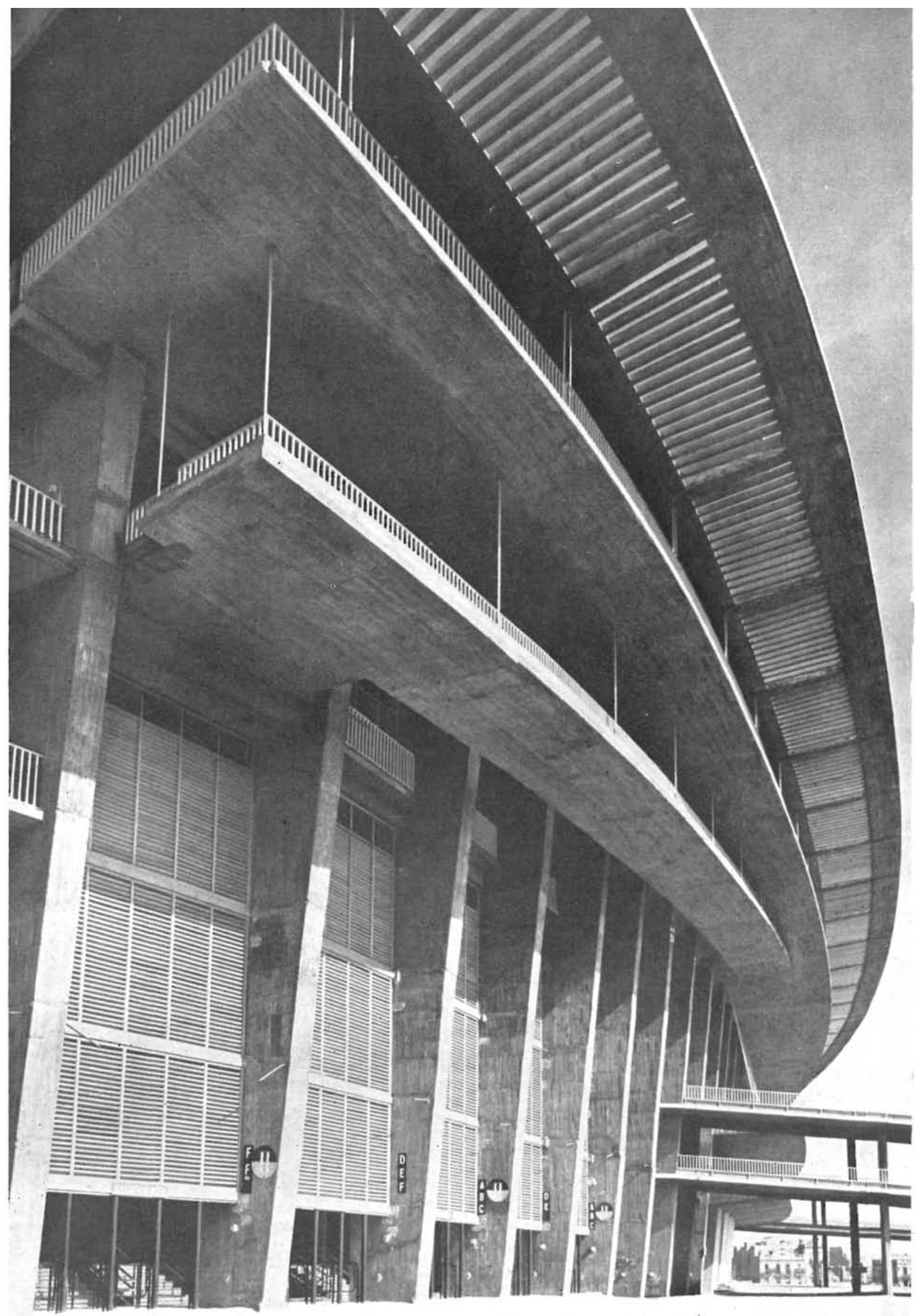



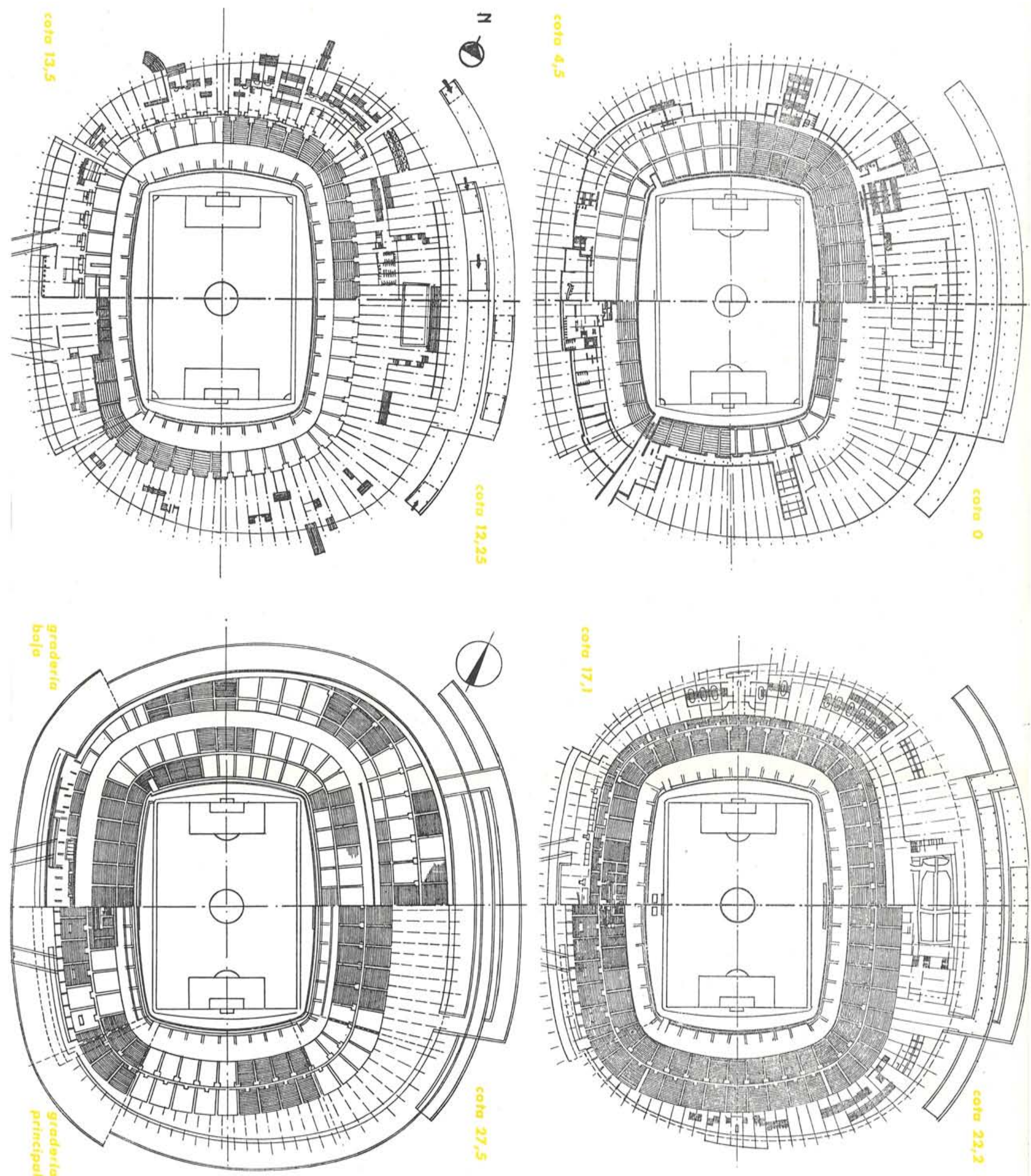

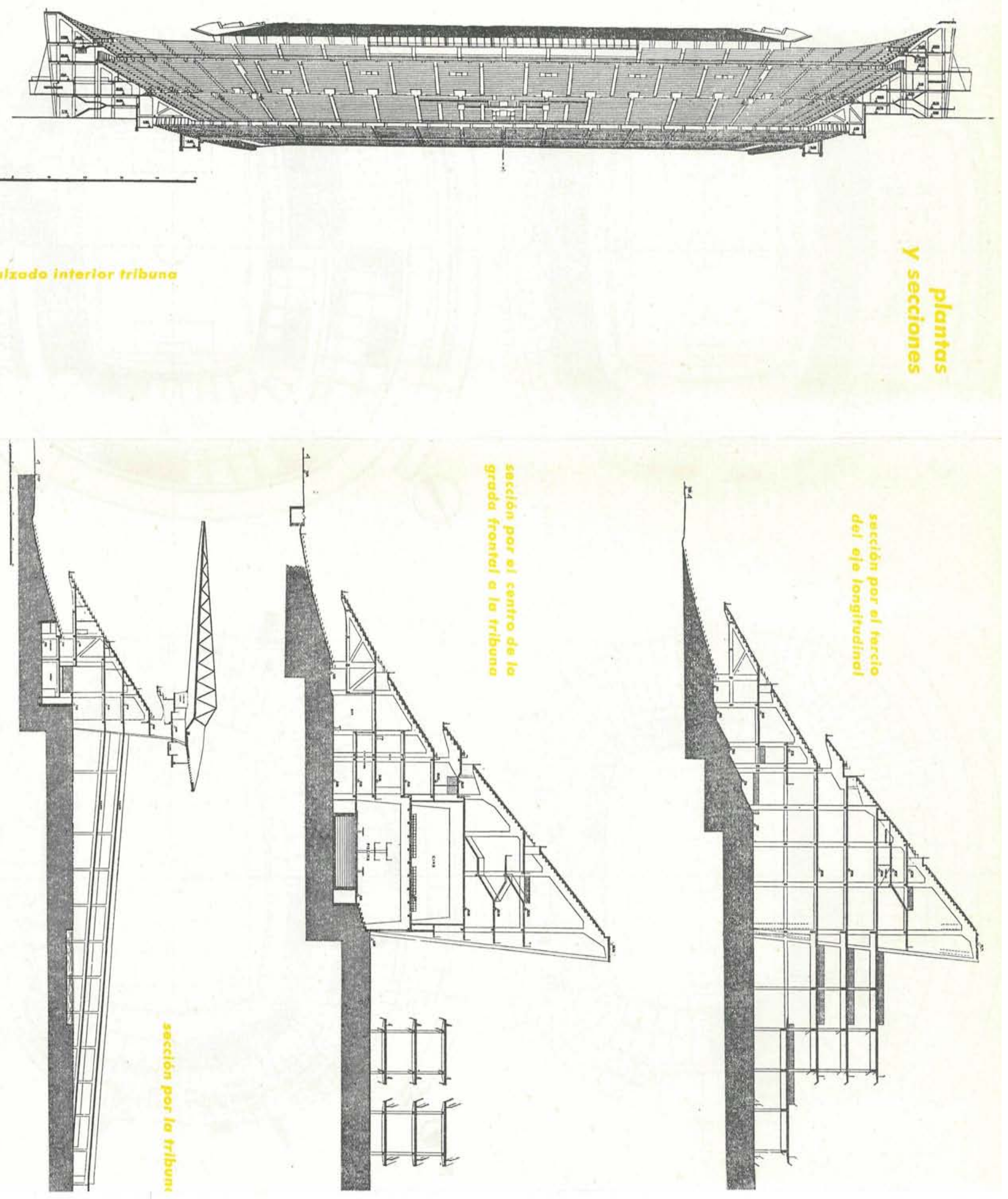

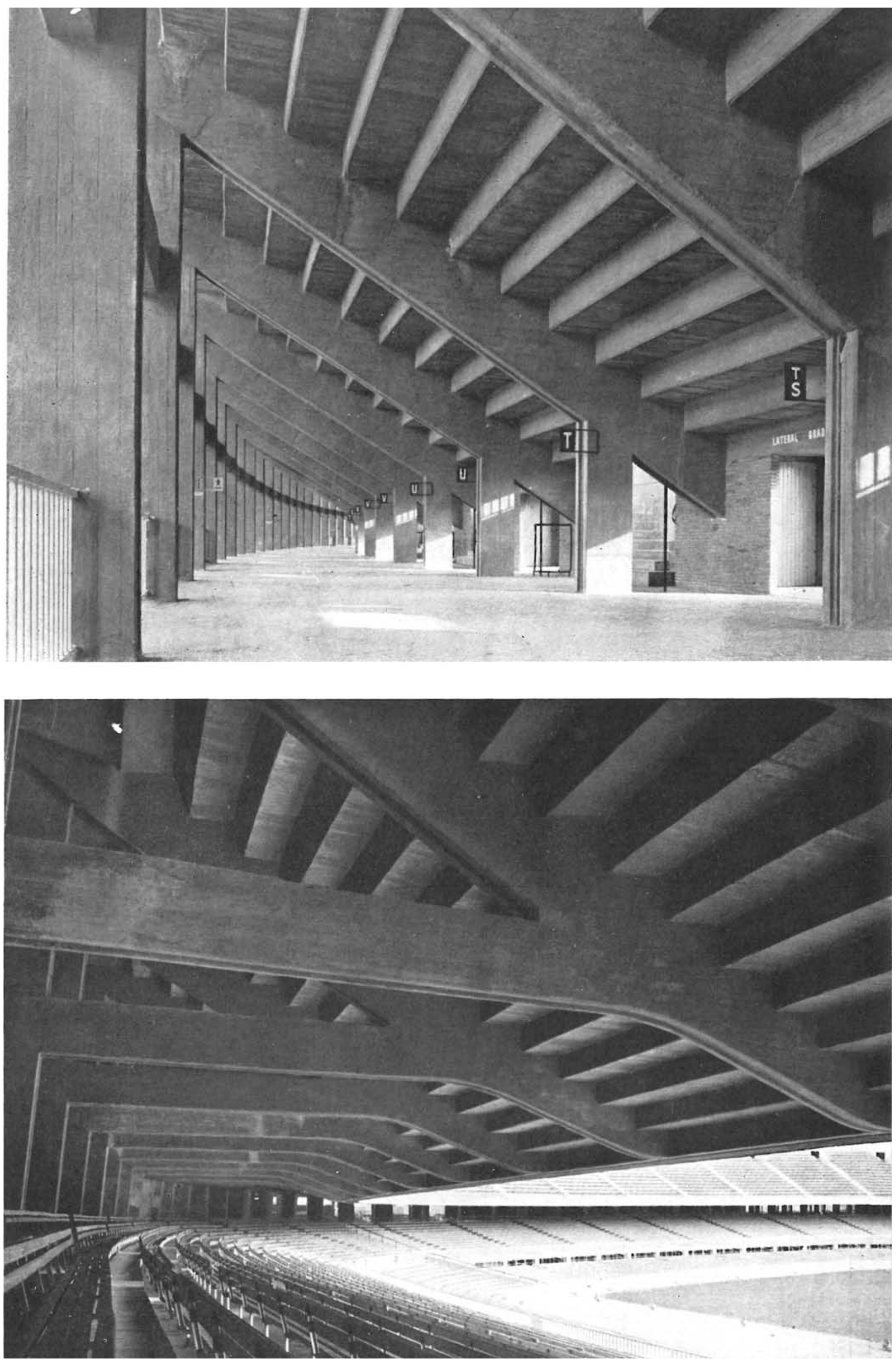

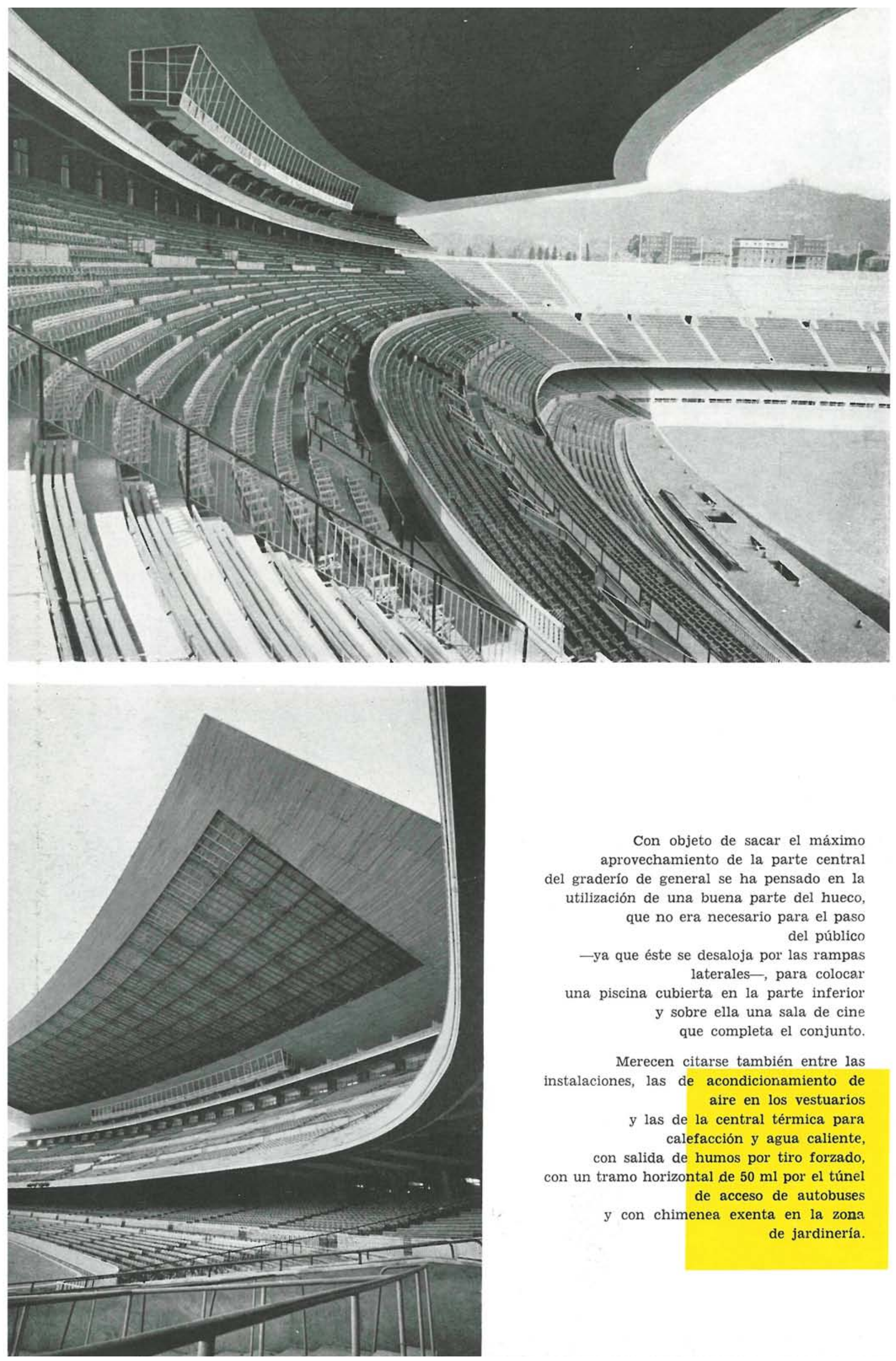

Con objeto de sacar el máximo aprovechamiento de la parte central del graderío de general se ha pensado en la utilización de una buena parte del hueco, que no era necesario para el paso del público -ya que éste se desaloja por las rampas laterales-, para colocar una piscina cubierta en la parte inferior y sobre ella una sala de cine que completa el conjunto.

Merecen citarse también entre las instalaciones, las de acondicionamiento de aire en los vestuarios y las de la central térmica para calefacción y agua caliente,

con salida de humos por tiro forzado, con un tramo horizontal de $50 \mathrm{ml}$ por el túnel de acceso de autobuses y con chimenea exenta en la zona de jardinería. 

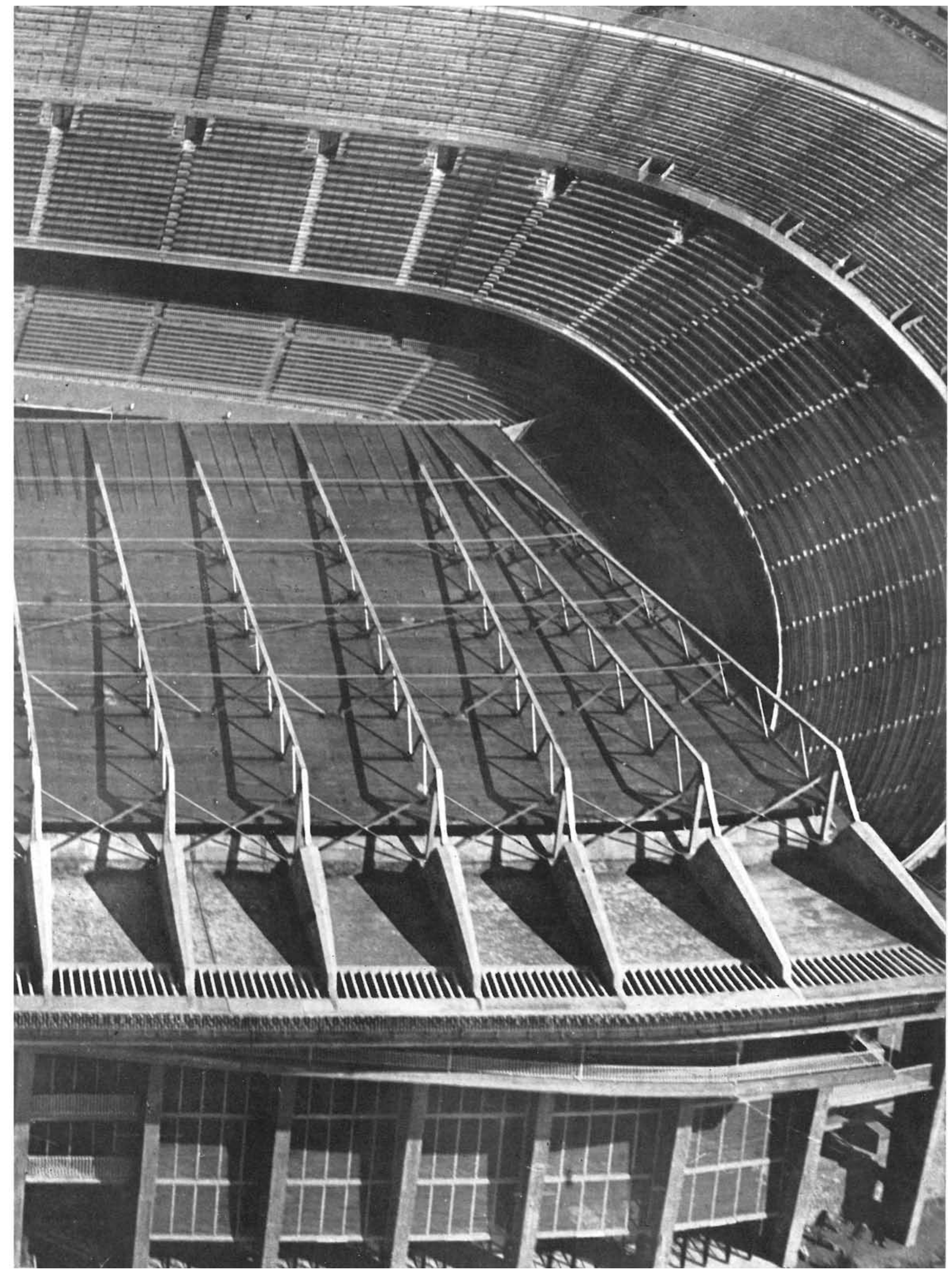